\title{
Techniques for the study of energy balance in man
}

\author{
Marinos Elia ${ }^{1 *}$, Rebecca Stratton ${ }^{1}$ and James Stubbs ${ }^{2}$ \\ ${ }^{1}$ Institute of Human Nutrition, University of Southampton, Southampton General Hospital, \\ Tremona Road, Southampton SO16 6YD, UK \\ ${ }^{2}$ ACERO, Rowett Research Institute, Bucksburn, Aberdeen AB21 9SB, UK
}

\begin{abstract}
Energy balance can be estimated in tissues, body segments, individual subjects (the focus of the present article), groups of subjects and even societies. Changes in body composition in individual subjects can be translated into changes in the energy content of the body, but this method is limited by the precision of the techniques. The precision for measuring fat and fat-free mass can be as low as $0.5 \mathrm{~kg}$ when certain reference techniques are used (hydrodensitometry, air-displacement plethysmography, dual-energy X-ray absorptiometry), and approximately $0.7 \mathrm{~kg}$ for changes between two time points. Techniques associated with a measurement error of $0.7 \mathrm{~kg}$ for changes in fat and fat-free mass (approximately $18 \mathrm{MJ}$ ) are of little or no value for calculating energy balance over short periods of time, but they may be of some value over long periods of time (18 MJ over 1 year corresponds to an average daily energy balance of $70 \mathrm{~kJ}$, which is $<1 \%$ of the normal dietary energy intake). Body composition measurements can also be useful in calculating changes in energy balance when the changes in body weight and composition are large, e.g. $>5-10 \mathrm{~kg}$. The same principles can be applied to the assessment of energy balance in body segments using dual-energy X-ray absorptiometry. Energy balance can be obtained over periods as short as a few minutes, e.g. during measurements of BMR. The variability in BMR between individuals of similar age, weight and height and gender is about 7-9\%, most of which is of biological origin rather than measurement error, which is about $2 \%$. Measurement of total energy expenditure during starvation (no energy intake) can also be used to estimate energy balance in a whole-body calorimeter, in patients in intensive care units being artificially ventilated and by tracer techniques. The precision of these techniques varies from 1 to $10 \%$. Establishing energy balance by measuring the discrepancy between energy intake and expenditure has to take into consideration the combined validity and reliability of both components. The measurement error for dietary intake may be as low as $2-3 \%$ in carefully controlled environments, in which subjects are provided only with certain food items and bomb calorimetry can be undertaken on duplicate samples of the diet. Reliable results can also be obtained in hospitalised patients receiving enteral tube feeding or parenteral nutrition as the only source of nutrition. Unreliability increases to an unknown extent in free-living subjects eating a mixed and varied diet; thus, improved methodology is needed for the study of energy balance.
\end{abstract}

Energy intake: Energy expenditure: Measurement techniques

The concept of energy balance is simple (energy balance $=$ energy intake - energy expenditure), but accurate and reliable measurements in free-living conditions may be far from easy and subject to problems with interpretation. Thus, some justification for undertaking energy balance studies is required, especially if the measurements are likely to be time-consuming and labour intensive. One of the purposes of undertaking energy balance studies is to help establish concepts concerning energy requirements in both health and disease. In clinical practice patients may eat very little as a result of poor appetite or difficulties in eating, swallowing or digesting food. Decisions about the adequacy of dietary intake may depend entirely on the health professional rather than the patient, and therefore some knowledge is required about energy requirements and how these are established. However, it should be stressed that the energy intake necessary to maintain energy balance is not necessarily the most appropriate intake. In depleted patients 
a positive energy balance is often required, not only to replete the reduced energy stores, but also to replete lean tissues (a positive energy balance favours a positive $\mathrm{N}$ balance). In contrast, in obese individuals a negative energy balance is desirable to reduce the risk of developing cardiovascular disease, diabetes and hypertension. Even in individuals with a desirable BMI and gross body composition, who are in energy balance, the intake required to maintain balance does not necessarily imply that it is optimal. If the individuals are very sedentary they would benefit from increased physical activity, which can improve cardio-respiratory function, well-being and reduce the risk of developing IHD (Liu et al. 2001). This increase in physical activity will of course also increase energy requirements.

Another reason for undertaking energy balance is to obtain information about mechanisms of depletion and repletion, information on the type of tissues that may be lost or gained (Elia, 1992b, 1997) and insights into physiological adaptations to changes in energy intake and/or expenditure. For example, a desirable regimen for producing weight loss in the obese (negative energy balance) is one that improves body composition and function. Excessive loss of lean body mass is not normally desirable, especially if it is associated with deterioration of tissue function (Shetty \& James, 1994; Elia, 2000). In contrast, in undernourished patients the nutritional treatment aims to accrete both lean and fat tissues, especially if they lead to improvements in body function. Regimens that result only in gain of fat may produce little or no functional benefit. Since energy balance can be estimated by measuring changes in body composition, the information can be used to assess whether the composition of weight change depends on the type of treatment and the magnitude of the energy imbalance. Other balance studies can provide information about the extent to which energy intake compensates for changes in physical activity and vice versa, which is important both from a physiological and clinical perspective. Some examples of how concepts of energy homeostasis can be obtained from different types of energy balance studies are illustrated below. These energy balance studies can be classified according to the type of measurements needed or not needed:

measurements of energy expenditure only: starvation studies (no energy intake);

measurements of changes in body composition only: no measurements of energy intake or expenditure;

measurements of energy intake and energy expenditure; measurements of energy intake or energy expenditure (or both) and changes in body composition.

Each type of study has advantages and disadvantages, which relate to the quality and kind of information it provides.

\section{Energy balance from measurements of energy expenditure only}

The general energy balance equation (energy balance $=$ energy intake - energy expenditure $)$ can be simplified when there is no dietary energy intake (energy balance $=-$ energy expenditure). Since measurements of BMR are undertaken after an overnight fast, they are essentially measurements of negative energy balance. Postprandial measurements of energy expenditure also represent measurements of negative energy balance. However, although the term 'energy balance' can be applied to periods ranging from $<1 \mathrm{~min}$ to a lifetime, it is not usually applied to these extreme ranges of time. An energy balance study of intermediate duration is the classic $31 \mathrm{~d}$ starvation trial of Benedict (1915), in which a subject was studied in a whole-body calorimeter. Use of the original data allows calculation of the cumulative negative energy balance. The pattern of cumulative energy loss from the body over the $31 \mathrm{~d}$ is shown in Fig. 1( $\mathrm{a}$ and $\mathrm{b}$ ), which also shows the contribution of BMR (Fig. 1(a)) and of protein oxidation (Fig. 1 (b)) to the cumulative energy loss, using reported daily values of BMR and urinary $\mathrm{N}$ values, assuming $1 \mathrm{~g}$ urinary $\mathrm{N}$ represents $116 \mathrm{~kJ}$ derived from oxidation of protein (Elia \& Livesey, 1992). The cumulative energy derived from protein oxidation $(32 \cdot 2 \mathrm{MJ})$ over the entire $31 \mathrm{~d}$ accounted for $17.9 \%$ of the total energy lost from the body $(180 \mathrm{MJ} ; 19 \cdot 8 \%$ when expressed relative to the BMR, which was $162.5 \mathrm{MJ})$. Total energy expenditure (TEE),

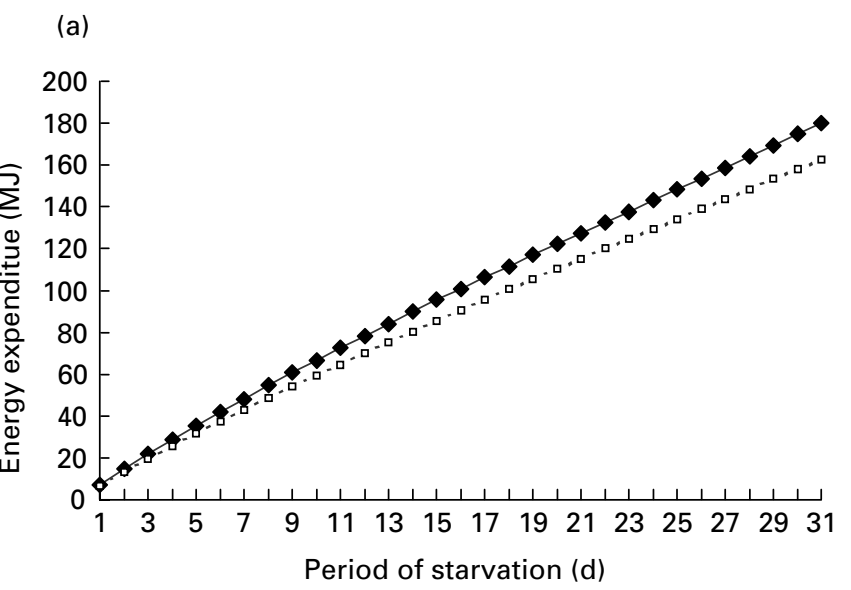

(b)

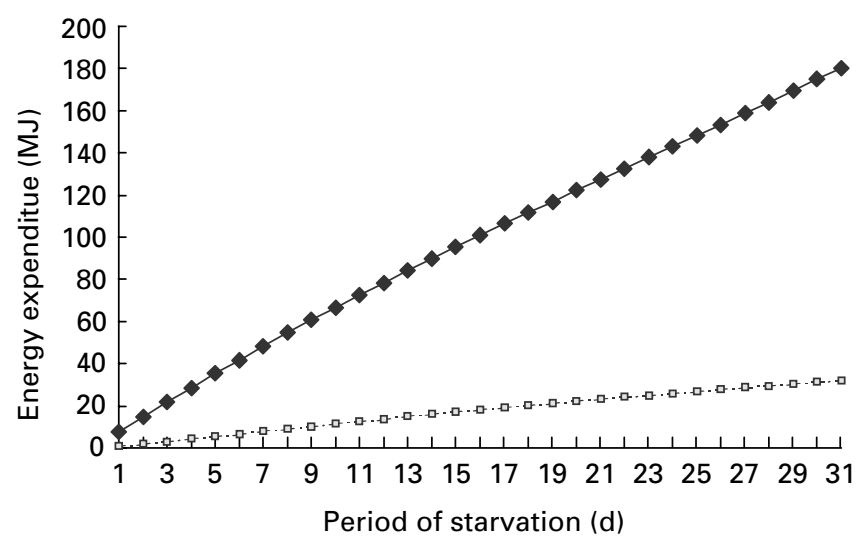

Fig. 1. Contribution of (a) BMR and (b) protein oxidation to the cumulative negative energy balance (cumulative energy expenditure) during $31 \mathrm{~d}$ of starvation. ( $-\bullet)$, Total energy expenditure; ( $\square-\square)$, contributions from BMI and from protein oxidation. (Calculations based on Benedict, 1915.) 
Table 1. Components of cumulative negative energy balance (total energy expenditure; TEE) and related indices during the first and second halves of a period of $31 \mathrm{~d}$ of total starvation (no energy) (based on data from Benedict, 1915)

\begin{tabular}{lccc}
\hline & $1-15 \mathrm{~d}$ & $16-31 \mathrm{~d}$ & $1-31 \mathrm{~d}$ \\
\hline TEE (MJ) & $95 \cdot 5$ & $84 \cdot 5$ & $180 \cdot 0$ \\
BMR (MJ) & $85 \cdot 5$ & $77 \cdot 0$ & $162 \cdot 5$ \\
Contribution of BMR to TEE (\%) & $89 \cdot 5$ & $91 \cdot 1$ & $90 \cdot 3$ \\
Physical activity level (TEE/BMR) & $1 \cdot 12$ & $1 \cdot 10$ & $1 \cdot 11$ \\
Protein oxidation: MJ & $17 \cdot 4$ & $14 \cdot 8$ & $32 \cdot 2$ \\
$\%$ TEE & $18 \cdot 2$ & $17 \cdot 5$ & $17 \cdot 9$ \\
$\%$ BMR & $20 \cdot 4$ & $19 \cdot 2$ & $19 \cdot 8$ \\
\hline
\end{tabular}

BMR and urinary $\mathrm{N}$ excretion tended to decrease with time, but when these results were expressed relative to each other there was little change. Table 1 illustrates these data by comparing the results obtained during the first and second halves of the semi-starvation period. The proportion of the energy expenditure derived from protein oxidation is similar to that observed in a number of other studies of lean subjects, but considerably higher than that obtained from obese subjects undergoing starvation (no energy intake) for $>2$ weeks. This reduced level in the obese can be regarded as an adaptation that allows prolonged survival. If during starvation obese subjects were to obtain the same proportion of energy from protein as lean subjects, they would rapidly deplete their lean tissues and die with substantial amounts of fat remaining in situ.

Undertaking energy balance studies in whole-body calorimeters allows good accuracy and precision to be established (see pp. 534-535), but they do not reflect freeliving conditions. The very low physical activity level (TEE/BMR), which was only $1 \cdot 11$ in the starvation study of Benedict (Table 1), probably reflects the direct effects of starvation as well as the artificial experimental conditions of the study. An energy balance technique that overcomes this problem involves measurement of changes in body composition between two time points, during which the subjects undertake their normal daily activities.

\section{Energy balance from measurements of changes in body composition}

Changes in fat and fat-free mass, measured using body composition techniques, can be used to establish energy balance by assigning energy values to the fat and fat-free body that is lost or gained. The energy value of body fat is well established (approximately $39 \cdot 4 \mathrm{MJ} / \mathrm{kg}$, assuming a metabolisability of 1.0; Elia \& Livesey, 1992), but there is more uncertainty about the energy density of the fat-free tissues that are lost or gained. However, if it is assumed that protein $(18 \cdot 5 \mathrm{MJ} / \mathrm{kg}$, also for a metabolisability of 1.0 ; Elia $\&$ Livesey, 1992) accounts for about $20 \%$ of the change in the fat-free body, then the energy density of fat-free mass that is gained or lost $(3.7 \mathrm{MJ} / \mathrm{kg})$ is only about $10 \%$ of that of the fat mass. Thus, in general, measurement of energy balance by body composition techniques depends predominantly on the accuracy and precision of measurement of fat mass (the partition of body weight into fat and fat-free
Table 2. Negative energy balance calculated from changes in body composition during the first and second halves of a period of 24 weeks of semi-starvation, and estimated protein and fat energy lost from the body*

\begin{tabular}{lccc}
\hline $\begin{array}{l}\text { Period of study } \\
\text { (weeks) }\end{array}$ & $\begin{array}{c}\text { Fat } \\
(\mathrm{MJ})\end{array}$ & $\begin{array}{c}\text { Protein } \\
(\mathrm{MJ})\end{array}$ & $\begin{array}{r}\text { Fat + protein } \\
(\mathrm{MJ})\end{array}$ \\
\hline $0-12$ & $207 \cdot 6$ & $25 \cdot 2$ & $232 \cdot 8$ \\
$12-24$ & $60 \cdot 3$ & $11 \cdot 8$ & $72 \cdot 1$ \\
$0-24$ (total) & $267 \cdot 9$ & $37 \cdot 0$ & $304 \cdot 9$ \\
\hline
\end{tabular}

*For details and assumptions, see p. 533; data calculated from Keys et al. (1950).

mass), rather than on the energy density of the fat-free mass (for more detailed discussion, see pp. 534-535). Changes in glycogen stores also make a contribution to the energy balance, but their effects are often small, especially in longterm studies involving major changes in body weight. Glycogen, which is part of the fat-free mass, has a similar energy density to protein and is lost from the body in approximately equivalent amounts of water to that associated with loss of protein.

The classic semi-starvation study, the Minnesota Study, of Keys et al. (1950) is used to illustrate the value of body composition techniques in establishing energy balance. It was chosen partly because the changes in fat and fat-free mass were large, and partly because various other measurements were obtained during the course of the study, which can be combined to provide insights into concepts about energy homeostasis (these other measurements will be presented in the subsequent section, see pp. 533-534). In this study, thirty-two subjects were semi-starved for a period of 24 weeks under carefully controlled conditions, during which they lost a mean of $24 \%$ of their initial body weight. The changes in body weight and composition that occurred during the first and second halves of the starvation period are shown in Table 2. Most of the weight loss was due to loss of fat-free mass ( $60 \%$ overall), but most of the negative energy balance was due to loss of fat mass ( $88 \%$ of the total, assuming that the energy equivalents of fat and fat-free mass lost are 39.4 and $3.7 \mathrm{MJ} / \mathrm{kg}$ respectively, as suggested earlier). These types of calculations have been applied to different groups of lean and obese individuals losing weight as a result of reduced food intake. Table 3 shows the results of the Minnesota Study, together with those of three other studies (Fuller et al. 1995; van Wijk, 1999; Gibney, 2002). These data are in general agreement with results obtained in a range of other studies and demonstrate that the contribution of lean tissues to total weight loss is greater in lean subjects than in obese subjects. The results also imply that the contribution of fat-free mass (mainly protein) to total energy lost from the body is also greater in lean subjects than in obese subjects.

There are several limitations in assessing energy balance from changes in body composition. One of these limitations concerns the precision of the method, which is considered later (pp. 534-535). Another limitation concerns the accuracy of body composition techniques; for example, water-dilution techniques assume that the hydration fraction of the fat-free mass is constant and hydrodensitometry 
Table 3. Contribution of fat-free mass (FFM) to weight loss and energy loss in lean and obese subjects during a period of semi-starvation*

\begin{tabular}{lccccc}
\hline & $\begin{array}{c}\text { Initial BMI } \\
\left(\mathrm{kg} / \mathrm{m}^{2}\right)\end{array}$ & $\begin{array}{c}\text { Amount of wt } \\
\text { loss }(\mathrm{kg})\end{array}$ & $\begin{array}{c}\text { Percentage wt loss } \\
\text { from FFM }\end{array}$ & $\begin{array}{c}\text { Percentage energy loss } \\
\text { from FFM (protein) }\end{array}$ & Reference \\
\hline Lean & $21 \cdot 7$ & $16 \cdot 8$ & 60 & 12 & Keys et al. (1950) \\
Obese & $21 \cdot 4$ & 4.6 & 58 & 2 & Gibney (2002) \\
& 33.0 & 10.1 & 19 & 2 & van Wijk (1999) \\
& $>40$ & 41.9 & 20 & 2 & Fuller et al. (1995) \\
\hline
\end{tabular}

*All results were obtained from experimental studies of semi-starvation, except the study of Fuller et al. (1995) in obese subjects, which was based on changes in body composition in morbidly-obese individuals undergoing gastroplasty.

assumes that the density of the fat-free mass is constant, neither of which is true when there are disturbances in fluid balance, such as oedema or dehydration. The fourcomponent model of body composition overcomes many of these problems but requires measurements of body density, total body water and bone mineral (Elia, 1992a; Fuller et al. 1992). Yet another limitation is that body composition techniques do not provide information about the mechanisms by which energy imbalance occurs. For example, the technique does not indicate whether a negative energy balance is achieved through changes in energy intake or expenditure, nor does it indicate the extent to which one of these components changes or compensates when the other is altered. In order to evaluate these factors it is usually necessary to make direct measurements of energy intake and expenditure. However, it is possible to measure one of these components and estimate the other, provided that changes in body composition are either assumed or measured (see pp. 533-534).

\section{Energy balance from measurements of energy intake and energy expenditure}

There is a vast literature on the methodology for assessing energy intake and expenditure. It is clear that energy balance studies based on measurements of energy intake and expenditure need to consider both practical and theoretical issues. In the present paper, only a few brief comments will be made:

1. energy expenditure can be measured more accurately and reproducibly in a whole-body calorimeter than in free-living conditions using tracer methods or other more indirect methods, including heart-rate monitors, accelerometers and activity diaries. Similarly, there is more confidence in energy intake measurements carried out in a metabolic facility, where food intake can be monitored more closely, than in free-living conditions. The precision and accuracy of some of these techniques are discussed in more detail (p. 534-535);

2. the introduction of dietary intake methodology can in itself alter dietary habits, at least in certain individuals (Bingham, 1991; Stallone et al. 1997). Theoretically, this situation may also apply to measurements of energy expenditure, although there has been little formal investigation of this possibility;

3. measurements of energy balance in more controlled conditions generally do not reflect those that occur in free-living conditions. There is also a general lack of statistical modelling of errors in energy balance in free-living conditions. These errors vary with the patient group, since it is recognised that obese subjects tend to underreport and patients with cognitive problems often provide unreliable reports of dietary intake and activities of daily living. Thus, there is a need to establish better methodology in free-living conditions;

4. there are specific problems associated with the use of particular dietary intake and expenditure methods. For example, there may be recall bias when dietary history is used to assess food intake. The weighed food intake method depends on the compliance of the individual to record everything that is eaten, whilst not changing typical eating patterns. However, there may be problems with both these assumptions. There may also be coding or calculation difficulties associated with various dietary intake methods (Bingham, 1987). Similarly, methods for measuring energy expenditure can pose specific problems. For example, accelerometers, which primarily measure movement rather than energy expenditure, may be inadequate for the assessment of the energy expended by subjects undertaking daily activities with varying proportions of weight-bearing activities (e.g. walking) and non-weight-bearing activities (e.g. lifting objects during heavy normal work). The use of heart-rate monitoring to measure energy expenditure is also problematic because of the wide variability of heart rate between subjects whilst undertaking a standardised activity. Thus, calibration of individual subjects is usually carried out using treadmill exercise, which is a weight-bearing activity that accounts for part of the energy cost of physical activity (the weight- and nonweight-bearing activities depend on the type of work and leisure activities undertaken by subjects). Calibration during heavy exercise is also not suitable for subjects with cardiac disease, especially those with arrhythmias. Furthermore, tracer techniques for measuring energy expenditure have not been adequately validated during rapid weight loss or gain. Many simple techniques that measure dietary intake and energy expenditure often forfeit accuracy and precision so that information can be obtained relatively non-invasively in large numbers of subjects in free-living conditions. However, there are some circumstances in which there is considerable confidence in the results obtained under normal environmental circumstances. For example, $24 \mathrm{~h}$ indirect calorimetry can be carried out in artificiallyventilated patients using normal or only slightly elevated concentrations of $\mathrm{O}_{2}$, whilst accurate volumes of feeds with known composition are administered. 
It is often not practical to obtain long-term measurements of both energy intake and expenditure in free-living or even in laboratory conditions. For example, no formal direct measurements of TEE were made before, during and after 6 months of semi-starvation in the Minnesota Study (Keys et al. 1950). However, it is possible to calculate energy expenditure and physical activity by combining energy balance measurements with those of energy intake. Conversely, energy intake can be calculated from measurements of body composition and energy expenditure. It is also possible to subdivide energy expenditure into its components to obtain insights into the factors responsible for energy imbalance and energy homeostasis.

\section{Combining measurements of body composition with energy intake or expenditure}

The total negative energy balance during 24 weeks of semistarvation in the Minnesota Study of Keys et al. (1950), which was estimated through changes in body composition (Table 3), can be converted to the mean daily balance by dividing the total negative energy balance by $168(24 \times 7 \mathrm{~d})$. Similarly, the values for the two 12-week periods can be obtained by dividing the changes in balance obtained during this period by $84(12 \times 7 \mathrm{~d})$. These values are shown in Table 4 . The energy intake of the individuals was carefully recorded during the entire 6 months of semi-starvation (also shown in Table 4). TEE during these periods, calculated as the sum of the negative energy balance and the energy intake values, averaged $8.38 \mathrm{MJ} / \mathrm{d}$, and was greater during the first 12 weeks $(9.55 \mathrm{MJ} / \mathrm{d})$ than during the second 12 weeks $(7 \cdot 21 \mathrm{MJ} / \mathrm{d})$.

Table 4 also shows the changes in physical activity energy expenditure, BMR and dietary-induced thermogenesis. The BMR measurements were made on three occasions, once before starvation and at 12 and 24 weeks of semi-starvation. The BMR value assigned to the first half of the study was the average of the first two measurements, the value for the second half of the study was the average of the last two measurements, and the overall value for the whole study was the average of all three measurements. The calculated BMR was based on measurements of $\mathrm{O}_{2}$ consumption, which was converted to energy expenditure using an energy equivalent of $4.8 \mathrm{kcal} / 1 \mathrm{O}_{2}\left(19.94 \mathrm{~kJ} / 1 \mathrm{O}_{2}\right)$. Dietary-induced thermogenesis can be assumed to be about $10 \%$ of energy intake, and physical activity energy expenditure can then be calculated as the difference. If no assumptions are made

Table 4. Components of negative energy balance $(\mathrm{MJ} / \mathrm{d})$ during the first and second halves of a period of 24 weeks of semi-starvation*

\begin{tabular}{lccc}
\hline & $\begin{array}{c}\text { Weeks } \\
0-12\end{array}$ & $\begin{array}{c}\text { Weeks } \\
12-24\end{array}$ & $\begin{array}{c}\text { Weeks } \\
0-24\end{array}$ \\
\hline Dietary intake & 6.78 & 6.35 & 6.57 \\
Negative energy balance & 2.77 & 0.86 & 1.81 \\
Total energy expenditure & 9.55 & 7.21 & 8.38 \\
Dietary-induced thermogenesis & 0.68 & 0.64 & 0.66 \\
BMR & 5.61 & 4.32 & 5.11 \\
Physical activity energy expenditure & 3.26 & 2.25 & 2.61 \\
\hline
\end{tabular}

${ }^{*}$ For details and assumptions, see p. 533; calculated from Keys et al. (1950). about dietary-induced thermogenesis, physical activity energy expenditure plus dietary-induced thermogenesis can be estimated as a single entity. Table 4 shows that the value during the first 12 weeks $(3 \cdot 26 \mathrm{MJ} / \mathrm{d})$ was greater than that during the second 12 weeks $(2 \cdot 25 \mathrm{MJ} / \mathrm{d}$; overall value for the 24-week period 2.61 MJ/d). Whilst this information is interesting, it does not indicate the pattern of changes that occur during the first or second halves of the study. Furthermore, they do not allow comparison with baseline (pre-starvation) measurements of TEE and physical activity, which makes it difficult to assess the extent of adaptation changes that may have been induced by dietary restriction. Since only one body composition measurement was made before starvation, it is obviously not possible to calculate changes in energy stores using body composition techniques. However, it is possible to estimate energy expenditure by assuming stability in body composition. The group was studied for several weeks immediately before starvation was started, and their weight was found to be stable whilst ingesting a diet of known energy content. For example, during the 3 weeks before semi-starvation the subjects lost only about $0 \cdot 10 \mathrm{~kg} /$ week, and so it could be assumed that the group was close to energy balance. Similarly, during the last 3 weeks of semi-starvation (weeks 22-24) it could be assumed that the group of subjects was close to energy balance because mean body weight decreased by only $0.11 \mathrm{~kg} /$ week. If allowances are made for this weight loss, using the energy densities of fat and fat-free tissues and the proportions in which they were lost in the study as a whole, the effect on TEE and energy balance would be $<0.30 \mathrm{MJ} / \mathrm{d}$, both before and during the last 3 weeks of semi-starvation. Since the dietary intake and BMR were measured before starvation was started and at 24 weeks, it is possible to calculate TEE (assuming energy balance for simplicity) and subdivide it into its components, as before. The results (Table 5 and 6) show that the reduction in TEE between the beginning and end of the weight-loss period was predominantly due to a reduction in physical activity, from $6.46 \mathrm{~kJ} / \mathrm{d}$ to $1.91 \mathrm{~kJ} / \mathrm{d}$, rather than $\mathrm{BMR}$, which decreased from $6.69 \mathrm{MJ} / \mathrm{d}$ to $4.09 \mathrm{MJ} / \mathrm{d}$. Thus, most of the energy conservation was achieved by behavioural change rather than a change in basal metabolism. Since the subjects followed a set schedule of activities, which included housekeeping and other laboratory activities, and walking 20 miles each week, it is reasonable to conclude that there was a major reduction in

Table 5. Components of energy balance and energy expenditure $(\mathrm{MJ} / \mathrm{d})$ during the 3 weeks immediately before semistarvation ( $-3-0$ weeks) and during the last 3 weeks of semistarvation (weeks 22-24)*

\begin{tabular}{lrcc}
\hline & $\begin{array}{c}\text { Weeks } \\
-3-0\end{array}$ & $\begin{array}{c}\text { Weeks } \\
22-24\end{array}$ & Change \\
\hline Dietary intake & 14.61 & 6.66 & 7.95 \\
Total energy expenditure & 14.61 & 6.66 & 7.95 \\
$\quad$ Dietary-induced thermogenesis & 1.46 & 0.66 & 0.80 \\
BMR & 6.69 & 4.09 & 2.06 \\
Physical activity energy & 6.46 & 1.91 & 4.55 \\
$\quad$ expenditure & & & \\
\hline
\end{tabular}

*Energy balance assumed; for details and other assumptions, see p. 533; calculated from keys et al. (1950). 
Table 6. Changes in total energy expenditure and its components between the baseline 3-week period before starvation and during the last 3 weeks of semi-starvation*

\begin{tabular}{lcccc}
\hline & & \multicolumn{2}{c}{ Change between baseline and end of semi-starvation period } \\
\cline { 2 - 4 } & Baseline $(\mathrm{MJ} / \mathrm{d})$ & $\mathrm{MJ} / \mathrm{d}$ & \% baseline & \% total reduction \\
\hline Dietary-induced thermogenesis & 1.46 & 0.80 & 55 & 10 \\
BMR & 6.69 & 2.60 & 39 & 33 \\
Physical activity energy expenditure & 6.46 & 4.55 & 70 & 57 \\
Total & 14.61 & 7.95 & 54 & 100 \\
\hline
\end{tabular}

*Energy balance during each 3-week period; for details and other assumptions, see p. 533; calculated from keys et al. (1950).

the energy expended in discretionary physical activities. Indeed, the subjects indicated that they felt weak and tired easily, as if they were 'old men'. The energy cost of walking on a treadmill at $3.5 \mathrm{miles} / \mathrm{h}$ at a $10 \%$ gradient was measured before, in the middle and at the end of the semistarvation period ( $n 10)$, and was found to be unchanged at $0.464,0.460$ and $0.464 \mathrm{~kJ} / \mathrm{kg}$ per min respectively. This finding indicates that the energy cost of this weight-bearing activity was reduced in proportion to body weight, which progressively decreased during the starvation period. If it can be assumed that the energy cost of other activities was also reduced in proportion to body weight, which is a reasonable first approximation for the type of activities undertaken by the subjects (this approximation may not apply when heavy prolonged physical work involves lifting objects), then it can be calculated that $64 \%$ of the reduction in physical activity energy expenditure was the result of a reduction in tasks, and $34 \%$ to a reduced cost of undertaking these tasks (i.e. a direct consequence of reduced body weight).

The decrease in BMR can also be partitioned into that due to the reduction in body cell mass $(65 \%)$ and that due to a reduction in BMR on a per $\mathrm{kg}$ body cell mass basis $(35 \%)$. Overall, $57 \%$ of the reduction in TEE between the basal pre-starvation period and the end of the starvation period was due to a reduction in the energy cost of physical activity (about two-thirds of which was due to a reduction in physical activities undertaken) and $33 \%$ to a reduction in BMR (about two-thirds of which was due to a reduction in body cell mass). The remaining $10 \%$ is attributed to a reduction in dietary-induced thermogenesis.

In these examples, TEE was used to estimate energy intake during a period of weight stability. More recent studies have estimated energy intake from measurements of TEE obtained by tracer techniques during periods of weight stability. Two tracer techniques have been used to estimate TEE in free-living conditions, the doubly-labelled water technique, which typically provides single estimates over about $10-20 \mathrm{~d}$ in adults, and the bicarbonate-urea method, which provides estimates of energy expenditure on a daily basis. Both techniques measure net $\mathrm{CO}_{2}$ production, which has to be converted to energy expenditure using an appropriate energy equivalent for $\mathrm{CO}_{2}$. It has been argued that tracer techniques are more accurate and/or reliable than many dietary intake methods, when the latter are used in isolation. Major discrepancies between dietary intake and expenditure during periods of weight stability have been attributed to underreporting of dietary intake, especially in certain groups of subjects, such as the obese. TEE:energy intake during periods of weight stability has been used to establish cut-off points for underreporting (Goldberg et al. 1991). However, in order to establish the cut-off points it is necessary to define weight stability, the period of time over which weight stability is measured and the precision and accuracy of the methods used. The issues on precision and accuracy of energy intake and expenditure methods are considered next, because they determine the accuracy and precision of energy balance. The precision of energy balance, assessed by changes in body composition, is also considered.

\section{Precision and accuracy of energy balance techniques}

\section{Changes in body composition}

The precision of various body composition techniques can vary considerably depending on the type of technique used, the compliance of the subject and the experience of the operator. With some reference body composition techniques, such as dual-energy X-ray absorptiometry, airdisplacement plethysmography and hydrodensitometry, and possibly water dilution, fat and fat-free mass may be estimated with a precision (1 SD) of about $0.5 \mathrm{~kg}$. Even a four-component model, which is based on a combination of air-displacement plethysmography (density), dual-energy $\mathrm{X}$-ray absorptiometry (bone mineral) and water dilution (water space), can give a precision close to $0.5 \mathrm{~kg}$, which translates to $19.7 \mathrm{MJ}$. However, when fat mass is overestimated by $0.5 \mathrm{~kg}$, fat-free mass is underestimated by $0.5 \mathrm{~kg}$, and vice versa. If it is assumed that $0.5 \mathrm{~kg}$ fat-free mass has an energy content of $1.9 \mathrm{MJ}$ (see earlier), the precision for the energy content of the body is $17.9 \mathrm{MJ}$ (19.7-1.9 MJ). For assessment of changes in energy stores (energy balance) by two independent body composition measurements the precision is $25.4 \mathrm{MJ}\left(\sqrt{ }(17.9)^{2}+(17.9)^{2}\right)$. This precision is equivalent to two to three times the energy intake when the changes in body composition are measured over $1 \mathrm{~d}$, but $<1 \%$ of the energy intake over 1 year. Fig. 2 is used to illustrate: (a) how this precision decreases when it is divided by the number of days between the two measurements; (b) how the precision can be improved by making two and four measurements per time point. For example, for a $2 \mathrm{~d}$ interval the precision improves from $12.7 \mathrm{MJ} / \mathrm{d}$ (one measurement per time point) to $8.98 \mathrm{MJ} / \mathrm{d}$ (two measurements per time point) and $6.35 \mathrm{MJ} / \mathrm{d}$ (four measurements per time point). Over a $20 \mathrm{~d}$ period the precision remains the same $(8.98 \mathrm{MJ} / \mathrm{d})$, but mean daily values are ten times lower 


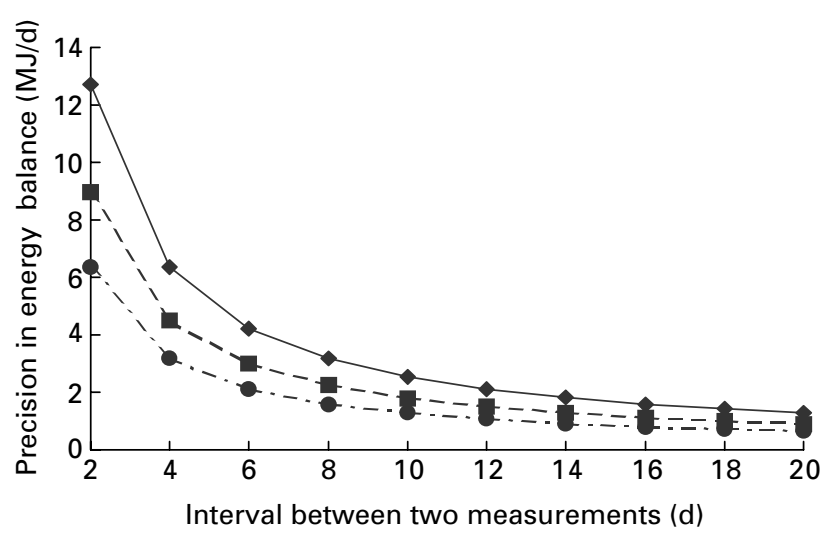

Fig. 2. Precision in energy balance $(\mathrm{MJ} / \mathrm{d})$, estimated from changes in body composition $(25.4 \mathrm{MJ})$, in relation to the duration of the study and number of measurements at each time point: $(-\downarrow)$, one measurement per time point; ( $\square-\mathbf{\square})$, two measurements per time point; (-๑), four measurements per time point.

(1.27, 0.90 and $0.64 \mathrm{MJ} / \mathrm{d}$ for one, two and four measurements per time point respectively).

The $\mathrm{CV}$ for indirect calorimetry is about $2 \%$ (same calorimeter). The analytical precision for measuring $\mathrm{CO}_{2}$ production by the doubly-labelled water technique has been found to range from $3 \%$ to $6 \%$ (Schoeller \& Hnilica, 1986; Elia et al. 2000), and for the bicarbonate-urea method from $2 \%$ to $3 \%$. Other methods for measuring energy expenditure, such as activity diaries, have a greater imprecision. For energy intake the CV may be as low as 2-3\% when duplicate food samples are collected under controlled conditions (e.g. in a metabolic facility or in studies of whole-body calorimetry) and analysed by bomb calorimetry. Reliable results can also be obtained in hospitalised patients receiving enteral tube feeding and parenteral nutrition. However, unreliability increases to an unknown extent in free-living subjects eating a mixed and varied diet. The extent is likely to vary depending on the technique used (e.g. dietary recall, weighed-food records), transcription errors and the type of subject. In recent years there has been increasing scepticism about the accuracy of dietary assessment, particularly in free-living subjects. Our recent studies (O'Reilley, 2002; Stubbs et al. 2003) have shown that when subjects are asked to record their intake in a metabolic suite, where independent and accurate methods for assessing dietary intake can be undertaken, they change their feeding behaviour (observation effect). They also misreport their actual intake (reporting effect). Thus, 'misreporting' comprises two separate but synchronous processes. There is also evidence that the problems can be considerably greater in free-living conditions, making assessment of energy balance more difficult than in the laboratory.

In view of this uncertainty it is difficult to establish the overall reliability of energy balance from measurements of both energy intake and energy expenditure. Thus, Fig. 3 shows the results obtained at three levels of precision of energy expenditure (CV of 3, 5 and $10 \%$, corresponding to $0.36,0.6$ and $1.2 \mathrm{MJ} / \mathrm{d}$ respectively), over a range of $\mathrm{CV}$ of

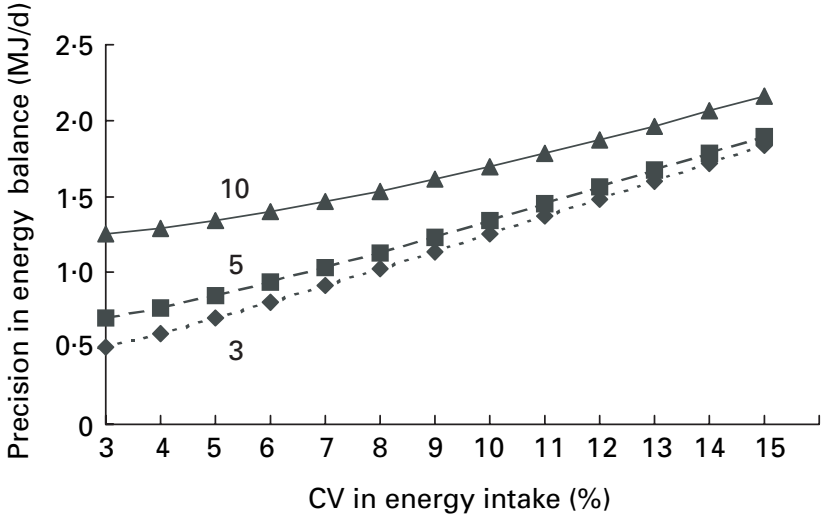

Fig. 3. Precision in estimated energy balance based on independent measurements of energy expenditure (at three levels of precision of $0.36(\bullet \cdots), 0.60(\boldsymbol{\square}-\mathbf{-})$ and $1.2(\boldsymbol{\Delta}-\boldsymbol{\Delta}) \mathrm{MJ})$ and energy intake (precision ranging from 0.4 to $1.8 \mathrm{MJ} / \mathrm{d}$ ).

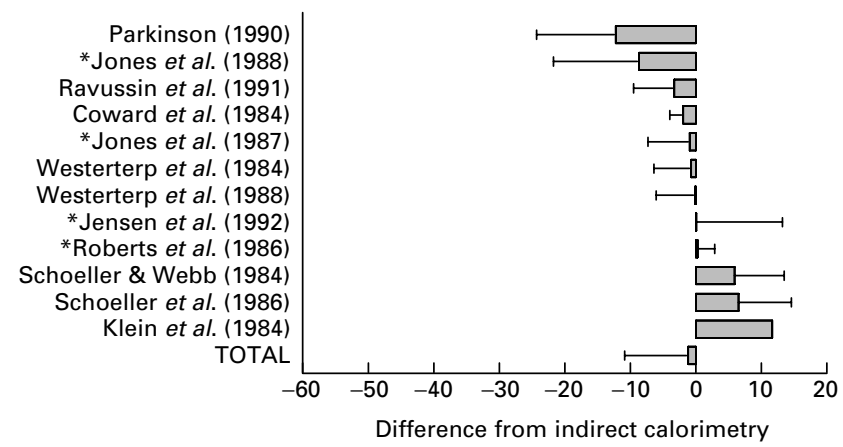

Fig. 4. Percentage difference in energy expenditure estimated by doubly-labelled water and indirect calorimetry $(100 \times$ doubly-labelled water/indirect calorimetry). Values are means and standard deviations represented by vertical bars. * Studies in infants; other studies involved adults.

energy intake of 3-15\%. The precision varies from about $0.5 \mathrm{MJ} / \mathrm{d}$ to $>2.0 \mathrm{MJ} / \mathrm{d}$.

Estimates of precision do not of course reflect the accuracy of a technique, since there may be a systematic bias between the measurement and the true value. For example, Fig. 4 shows the results of twelve studies (seven in adults ( $n$ 50) and five in children ( $n$ 34)) when compared with indirect calorimetry, which is regarded as a reference 'gold' standard. The values shown represent the bias (systematic difference from indirect calorimetry), and the standard deviation of this difference. For the group as a whole the results obtained by the doubly-labelled water method differed from indirect calorimetry by $-1 \cdot 3$ (SD 10.9) $\%$ ( $n$ 84), with similar results in adults ( -0.6 (SD 11.0) \%; $n$ 50) and children $(-2 \cdot 2$ (SD 10.9) \%; $n$ 34). The extent of disagreement between the two techniques was not related to gender or the duration of study. One study found that as the amount of fat increased, the doubly-labelled water method progressively underestimated energy expenditure obtained by indirect calorimetry $(r-0.81 ; P<0.002$; Ravussin et al. 1991). It should also be noted that the doubly-labelled-water 
method assumes that the rates of $\mathrm{CO}_{2}$ turnover, the size of the total water pool and the background enrichment of isotopes are constant over time, none of which is likely to be true. Since these factors are likely to vary more in freeliving conditions than in carefully-controlled metabolic studies that have set out to establish constancy, the accuracy and precision of results obtained in free-living conditions are likely to be worse. The discrepancy between whole-body indirect calorimetry and the bicarbonate-urea method $(-0 \cdot 2$ (SD 3.3) $\%$ or $-0.05(\mathrm{SD} \mathrm{3.1)} \mathrm{MJ/d)} \mathrm{has} \mathrm{been} \mathrm{found} \mathrm{to} \mathrm{be}$ small, but these values represent results obtained only by our group.

\section{Conclusion}

The concept of energy balance can be applied to human tissues in vivo, to individual subjects, to groups of subjects and even to societies (e.g. energy balance during development and recovery from famines by measuring the discrepancy between estimated energy requirements and disappearance of food supply). These different categories of energy balance measurements require different sets of specific assumptions and calculations from those indicated in the present paper for individual human subjects.

The most accurate and precise short-term measurements of energy balance are usually obtained in artificial environments, which cannot be generalised to real-life conditions. For example, direct measurements of gaseous exchange are not normally undertaken in real-life conditions, although they can be measured over $24 \mathrm{~h}$ under normal circumstances in artificially-ventilated patients who are infused with a known amount of energy either enterally or parenterally. In recent years advances have been made in measuring energy expenditure in free-living subjects using tracer techniques, but it is necessary to take into account their accuracy and precision. In addition, estimation of energy balance requires measurements of energy intake, which has an uncertain accuracy or precision in free-living conditions, particularly in different groups of individuals who may be suffering from various diseases. Advances in body composition techniques can also provide better information about changes in energy stores between two time points, but their precision is inadequate for establishing short-term changes in energy balance, ranging from $1 \mathrm{~d}$ to a few days, in individual subjects. They are of more value for groups of subjects, for large changes in body composition and for studies of longer duration. However, the assessment of energy balance, by measuring changes in body composition, does not provide insights into the dynamics and interrelationships of energy intake, energy expenditure and their components. There is a need to develop better methodology for the study of energy balance in free-living subjects, with and without disease.

\section{References}

Benedict FG (1915) A Study of Prolonged Fasting. Carnegie Institute of Washington Publication no. 203. Washington, DC: Carnegie Institute of Washington.
Bingham S (1987) The dietary assessment of individuals; methods, accuracy, new techniques and recommendations. Nutrition Abstracts and Reviews 57, 705-742.

Bingham SA (1991) Limitations of the various methods for collecting dietary intake data. Annals of Nutrition Metabolism 35, 117-127.

Coward WA, Prentice AM, Murgatroyd PR, Goldberg GR, Halliday D, MacNamara JP, Davies HL, Cole TJ \& Sower M (1985) Measurement of $\mathrm{CO}_{2}$ and water production rate in man using ${ }^{2} \mathrm{H},{ }^{18} \mathrm{O}$-labelled $\mathrm{H}_{2} \mathrm{O}$; comparisons between calorimeter and isotope values. In Human Energy Metabolism, Physical Activity and Energy Expenditure Measurements in Epidemiological Research Based upon Direct and Indirect Calorimetry. Report of an EC Workshop at Wageningen, The Netherlands: Euro-Nutr Report no. 5, pp. 126-128 [AJHV Esk, editor]. Den Haag, The Netherlands: CIP-Gegevens Koninklijke.

Elia M (1992a) An evaluation of two and more than two component models of body composition. Clinical Nutrition 11, 114-127.

Elia M (1992b) Organ and tissue contribution to metabolic rate. In Energy Metabolism: Tissue Determinants and Cellular Corollaries, pp. 61-79 [JM Kinney and HN Tucker, editors]. New York: Raven Press.

Elia M (1997) Tissue distribution and energetics in weight loss and undernutrition. In Physiology, Stress and Malnutrition. Functional Correlates and Nutritional Intervention, pp.383-412 [JM Kinney and HN Tucker, editors]. New York: LippincottRaven Publishers.

Elia M (editor) (2000) Detection and Management of Undernutrition in the Community. A Report by The Malnutrition Advisory Group (A Working Group of The British Association for Parenteral and Enteral Nutrition). Maidenhead, Berks.: British Association for Parenteral and Enteral Nutrition.

Elia M \& Livesey G (1992) Energy expenditure and fuel selection in biological systems: the theory and practice of calculations based on indirect calorimetry and tracer methods. International Journal of Nutrition and Dietetics 70, 68-131.

Elia M, Ritz P \& Stubbs RJ (2000) Energy expenditure in the elderly. European Journal of Clinical Nutrition 54, Suppl. 3, S92-S103.

Fuller NJ, Jebb SA, Laskey MA, Coward WA \& Elia M (1992) Four-component model for the assessment of body composition in humans: comparison with alternative methods and evaluation of the density and hydration of fat-free mass. Clinical Science 82, 687-693.

Fuller NJ, Sawyer MB \& Elia M (1995) Body composition changes after vertical band gastroplasty in obese females. Proceedings of the Nutrition Society 54, 95A.

Gibney ER (2002) The physical, psychological and metabolic effects of nutritional depletion and subsequent repletion. PhD Thesis, University of Cambridge.

Goldberg GR, Blaak AE, Jebb SA, Cole TJ, Murgatroyd PR, Coward WA \& Prentice AM (1991) Critical evaluation of energy intake data using fundamental physiological principles of energy physiology. 1. Derivation of cutoff limits to identify under-recording. European Journal of Clinical Nutrition 45, $569-581$.

Jensen CL, Butte NF, Wong WW \& Moon JK (1992) Determining energy expenditure in preterm infants: comparison of $2 \mathrm{H}(2) 18 \mathrm{O}$ method and indirect calorimetry. American Journal of Physiology 263, R685-R692.

Jones PJ, Winthrop AL, Schoeller DA, Filler RM, Swyer PR, Smith J \& Heim T (1988) Evaluation of doubly labeled water for measuring energy expenditure during changing nutrition. American Journal of Clinical Nutrition 47, 799-804.

Jones PJ, Winthrop AL, Schoeller DA, Swyer PR, Smith J, Filler RM \& Heim T (1987) Validation of doubly labeled water for 
assessing energy expenditure in infants. Pediatric Research 21, 242-246.

Keys A, Brozek J, Henschel A, Mickelsen O \& Taylor HL (1950) The Biology of Human Starvation, pp. 81-535. Minneapolis, MN: University of Minnesota Press.

Klein PD, James WPT, Wong WW, Irving CS, Murgatroyd PR, Cabrera M, Dallosso HM, Klein E \& Nichols BL (1984) Calorimetric validation of the doubly-labelled water method for determination of energy expenditure in man. Human Nutrition Clinical Nutrition 38C, 5-106.

Liu P, Arnold M, Belenkie I, Howlett J, Huckell V, Ignazewski A et al. (2001) The 2001 Canadian Cardiovascular Society consensus guideline update for the management and prevention of heart failure. Canadian Journal of Cardiology 17, 5E-25E.

O'Reilley L (2002) Mis-reporting of food intake in UK adults. PhD Thesis, University of Coleraine.

Parkinson SA (1990) In vivo measurement of changes in body composition. PhD Thesis, University of Cambridge.

Ravussin E, Harper I, Rising R \& Bogardus C (1991) Energy expenditure by doubly labelled water: validation in lean and obese subjects. American Journal of Physiology 261, E402-E409.

Roberts SB, Coward WA, Schlingenseipen K-H, Nohria V \& Lucas A (1986) Comparison of the doubly labeled water $\left({ }^{2} \mathrm{H}_{2}{ }^{18} \mathrm{O}\right)$ method with indirect calorimetry and a nutrient-balance study for simultaneous determination of energy expenditure, water intake and metabolizable energy intake in preterm infants. American Journal of Clinical Nutrition 44, 315-322.

Schoeller DA \& Hnilica JM (1986) Reliability of the doubly labelled water method for the measurement of total energy expenditure in free-living subjects. Journal of Nutrition 126, 348S-354S.
Schoeller DA, Ravussin E, Schutz Y, Acheson KJ, Baertschi P \& Jequier E (1986) Energy expenditure by doubly labeled water: validation in humans. American Journal of Physiology 250, R823-R830.

Schoeller DA \& Webb P (1984) Five-day comparison of the doubly labeled water method with respiratory gas exchange. American Journal of Clinical Nutrition 40, 153-158.

Shetty PS \& James WPT (1994) Body Mass Index: A Measure of Chronic Energy Deficiency in Adults. FAO Food and Nutrition Paper no. 56, pp. 1-57. Rome: FAO.

Stallone DD, Brunner EJ, Bingham SA \& Marmot MG (1997) Dietary assessment in Whitehall II: the influence of reporting bias on apparent socioeconomic variation in nutrient intakes. European Journal of Clinical Nutrition 51, 815-825.

Stubbs RJ, O'Reilley L, Fuller Z, Horgan G, Meyer C, Deary I, Austin E, Ritz P, Milne E \& James WPT (2003). Detecting and Modelling Mis-reporting of Food Intake in Adults. London: Food Standards Agency.

van Wijk MCW (1999) The assessment of body composition in obese subjects using bioelectrical impedance spectroscopy. $\mathrm{PhD}$ Thesis, University of Aberdeen.

Westerterp KR, Brouns F, Saris WHM \& Hoor FP (1988) Comparison of doubly labelled water with respirometry at low and high activity levels. Journal of Applied Physiology $\mathbf{6 5}$, 53-56.

Westerterp KR, Schoffelen PFM, Saris WHM \& ten Hoor F (1984) Measurement of energy expenditure using doubly labelled water, a validation study. Report of Instituut voor de Voeding, pp. 129-131. Maastricht, The Netherlands: Instituut voor de Voeding. 